\title{
Pengaruh Pengungkapan Sustainability Report Terhadap Kinerja Pasar
}

\author{
Monica Suwandi \\ Universitas Katolik Soegijapranata Semarang \\ monicasuwandi@gmail.com
}

\begin{abstract}
The purpose of this study is to examine the relationship between sustainabilty report disclosure and financial performance. This research employs all companies listed on the Indonesian Stock Exchange (IDX) over period of 2012-2016. The sample was collected under purposive sampling technique. Results indicate that the sustainability report economy dimension, sustainability report environment dimension, sustainabilty report social dimension, and quality audit have effect on the financial performance measured by return on asset and price earnings ratio. In addition, sustainability report human right dimension has effect on profitability, but no effect on the finacial performance market.
\end{abstract}

Keywords: sustainability report, financial performance, quality audit.

\begin{abstract}
Abstrak
Penelitian ini bertujuan untuk menguji hubungan antara pengungkapan sustainability report dengan kinerja keuangan. Penelitian ini menggunakan semua perusahaan yang terdaftar di Bursa Efek Indonesia tahun 2012-2016. Sampel pada penelitian ini diambil dengan teknik purposive sampling. Hasil pengujian pada penelitian ini menunjukkan bahwa sustainability report dimensi ekonomi, sustainability report dimensi lingkungan, sustainability report dimensi sosial, dan kualitas audit berpengaruh terhadap kinerja keuangan yang diukur dengan return on asset dan price earnings ratio. Sebagai tambahan, sustainability report dimensi hak asasi manusia berpengaruh terhadap profitabilitas tetapi tidak berpengaruh terhadap kinerja keuangan pasar.
\end{abstract}

Kata kunci: sustainability report, kinerja keuangan, kualitas audit.

\section{PENDAHULUAN}

Kinerja perusahaan merupakan hasil dari banyak keputusan individual yang dibuat secara terus menerus oleh manajemen. Kinerja perusahaan tercermin dari kinerja keuangan dan kinerja pasar. Kinerja pasar tercermin dari pergerakan harga saham perusahaan. Kinerja keuangan dan kinerja pasar saling berkaitan. Perusahaan yang mampu menunjukkan kinerja keuangan yang baik akan mendapat respon positif para pelaku pasar modal sehingga mendorong kenaikan harga saham. Apabila harga saham terus mengalami peningkatan, maka investor juga mendapat keuntungan dari return saham. Salah satu indikator yang dapat digunakan untuk menilai kemampuan perusahaan dalam memberikan return yang tinggi kepada investor adalah price earning ratio (PER). Perusahaan yang memiliki rasio PER yang 
tinggi menunjukkan bahwa saham perusahaan sangat diminati oleh para investor. Berbagai faktor dapat mempengaruhi rasio ini dan yang terbaru adalah kecenderungan investor untuk mengapresiasi perusahaan yang melaporkan sustainability report.

Sebagian perusahaan di Indonesia masih menekankan laporan yang berkaitan dengan kinerja keuangan semata. Namun, wacana tentang perubahan iklim dan tanggung jawab sosial perusahaan telah mengalihkan perhatian investor terhadap isu-isu lingkungan. Agar minat investor terhadap saham perusahaan tetap terjaga, perusahaan harus memberikan respon terhadap perubahan perilaku investor yang lebih menekankan pada aspek-aspek sosial lingkungan. Kondisi keuangan yang baik saja belum cukup untuk menyakinkan investor dalam membeli saham perusahaan jika pertumbuhan tersebut harus mengorbankan lingkungan alam dan sosial. Perlu perhatian serius agar perusahaan bertumbuh secara sustainable (berkelanjutan). Dengan tuntutan para stakeholder terhadap pertanggungjawaban sosial dan lingkungan maka perusahaan harus dengan suka rela mengungkapkan laporan keberlanjutan atau sustainability report.

Sustainability Report pertama kali digagas oleh Global Reporting Inisiatives (GRI) pada tahun 1999 yang menyajikan pelaporan informasi sosial, lingkungan dan keuangan secara terpadu dalam satu paket pelaporan korporasi. Penelitian yang dilakukan Jackson et.al. (2011) mengungkapkan bahwa sustainability reporting dan konsep triple bottom line merupakan dua hal yang tidak bisa dipisahkan. Apabila perusahaan mempedulikan konsep triple bottom line maka perusahaan juga memiliki perhatian penuh terhadap sustainability reporting.

Penelitian ini bertujuan untuk menguji pengaruh pengungkapan sustainability report terhadap kinerja pasar perusahaan. Kinerja perusahaan diproksikan dengan price earnings ratio. Perusahaan yang melaporkan sustainability report diprediksi memiliki kinerja keuangan yang baik. Lebih spesifik, ada empat dimensi dari sustainability report yang akan diuji yaitu dimensi ekonomi, dimensi lingkungan, dimensi sosial, dan dimensi hak asasi manusia. Perusahaan yang melaporkan sustainability report diprediksi memiliki profitabilitas yang tinggi dan kinerja saham yang baik.

\section{TINJAUAN LITERATUR DAN PERUMUSAN HIPOTESIS}

Menurut GRI, sustainability report adalah laporan yang mengungkapkan aktivitas perusahaan kepada pihak internal maupun eksternal sebagai tanggung jawab organisasi dalam mewujudkan tujuan pembangunan berkelanjutan. Sustainability report terdiri dari empat dimensi: 1) Dimensi ekonomi menyangkut dampak organisasi pada kondisi ekonomi stakeholder dan pada sistem ekonomi di tingkat lokal, nasional, dan global. Aspek ekonomi yang dilaporkan dalam laporan keberlanjutan lebih pada kontribusi perusahaan terhadap besar sistem ekonomi. 2) Dimensi lingkungan menyangkut implikasi langsung aktivitas perusahaan terhadap ekosistem, baik yang hidup maupun yang tidak hidup. Pengungkapan dimensi lingkungan dalam sustainability report dinilai penting untuk meningkatkan reputasi dan kepercayaan stakeholder karena dengan mengungkapkan kinerja lingkungan maka perusahaan menunjukkan eksistensi dan partisipasi perusahaan dalam menangani masalah lingkungan. 3) Dimensi masyarakat berkaitan dengan dampak organisasi terhadap masyarakat sekitar dan risiko yang dihadapi perusahaan dari institusi sosial lainnya. 4) Dimensi hak asasi manusia berkaitan dengan penghargaan perusahaan terhadap hak asasi manusia karyawan, nondiskriminasi, kebebasan berserikat, tenaga kerja anak, hak adat, serta kerja paksa, dan kerja wajib. 


\section{Dimensi Ekonomi Dan Kinerja Pasar .}

Dalam menjalankan aktivitas operasional sehari-hari, perusahaan membutuhkan dukungan dana dari berbagai pihak, salah satunya adalah investor. Sebagai pihak penyedia dana, perusahaan bertanggung jawab terhadap investor dalam menyediakan informasi yang andal berkaitan dengan kondisi ekonomi makro dan memberikan analisis yang dapat membantu investor mengukur dampak perubahan dari indikator ekonomi makro terhadap kinerja perusahaan di masa mendatang. Perusahaan yang melakukan pengungkapan sustainability report memberi sinyal kepada investor bahwa perusahaan sungguh-sungguh perduli terhadap isu-isu ekonomi makro dan telah melakukan upaya-upaya yang diperlukan untuk mengantisipasi efek positif atau negatif dari perubahan-perubahan ekonomi makro terhadap kinerja perusahaan. Investor akan lebih percaya kepada perusahaan dan memperlihatkan kepercayaan tersebut dengan membeli saham perusahaan. Hubungan sustainability report dan peningkatan harga saham dinyatakan dalam hipotesis berikut ini:

\section{H1 : Pengungkapan sustainability report dimensi ekonomi berpengaruh positif terhadap kinerja pasar.}

\section{Dimensi Lingkungan dan Kinerja Pasar}

Pengungkapan sustainability report dimensi lingkungan sangat penting untuk diterapkan dalam perusahaan. Hal ini dikarenakan, suatu perusahaan yang melaporkan pertanggungjawaban terhadap lingkungan akan dianggap sebagai perusahaan yang memiliki nama baik karena ikut menjaga dan melestarikan alam sekitar. Aktivitas keberlanjutan juga merupakan salah satu upaya organisasi untuk berkontribusi terhadap sustainable development. Sustainable development bertujuan untuk pemenuhan kebutuhan manusia dan meningkatkan kualitas kehidupan manusia. Dengan adanya pengungkapan sustainabilty report dimensi lingkungan citra perusahaan di mata investor akan meningkat. Jika perusahaan perduli terhadap lingkungan, investor akan tertarik untuk membeli saham sehingga kinerja pasar akan meningkat. Berdasarkan uraian tersebut hipotesis kedua di rumuskan sebagai berikut:

\section{H2 : Pengungkapan sustainability report dimensi lingkungan berpengaruh positif terhadap kinerja pasar.}

Tidak jauh berbeda dengan dimensi lainnya, dimensi sosial juga sangat penting untuk diterapkan dalam perusahaan. Apabila perusahaan melaporkan sustainability report dimensi sosial maka perusahaan akan dianggap sebagai perusahaan yang memiliki jiwa sosial yang tinggi, memiliki rasa kasih sayang terhadap sesama, serta perusahaan yang memiliki simpati maupun empati yang tinggi. Citra perusahaan di mata investor akan meningkat sehingga menarik lebih banyak investor membeli saham perusahaan. Kepedulian terhadap masalahmasalah sosial juga bisa meningkatkan moral karyawan untuk bekerja lebih sungguh-sungguh demi mewujudkan tujuan perusahaan. Jadi, keperdulian terhadap lingkungan sosial membawa dampak positif terhadap prospek perusahaan ke depan dan akan mendorong meningkatnya harga saham perusahaan. Berdasarkan uraian tersebut, hubungan antara dimensi sosial dan nilai saham perusahaan dirumuskan dalam hipotesis tiga berikut ini:

\section{H3 : Pengungkapan sustainability report dimensi sosial berpengaruh positif terhadap kinerja pasar.}




\section{Dimensi Hak Asasi Manusia dan Kinerja Pasar}

Pengungkapan sustainability report dimensi hak asasi manusia menyangkut dampak sebuah organisasi menyangkut sejauh mana hak asasi manusia diperhitungkan dalam investasi dan praktek pemilihan supplier/kontraktor. Misalnya keselamatan karyawan, perusahaan memastikan bahwa tempat kerja aman bagi karyawan dengan memantau secara ketat proses produksi. Beberapa tindakan pencegahan adalah memeriksa mesin dan peralatan guna memastikan bahwa semuanya berfungsi dengan baik, mengharuskan digunakannya kacamata keselamatan atau peralatan lainnya yang dapat mencegah terjadinya cedera, dan menekankan tindakan pencegahan khusus dalam seminar-seminar pelatihan. Hal ini menambah nilai lebih dimata investor sehingga investor lebih percaya untuk menanamkan modalnya diperusahaan. Semakin banyak investor yang membeli saham perusahaan, maka harga saham akan naik. Jika perusahaan perduli terhadap hak asasi manusia, investor akan tertarik untuk membeli saham sehingga kinerja pasar akan meningkat. Berdasarkan uraian tersebut hipotesis empat dinyatakan sebagai berikut:

\section{H4 : Pengungkapan sustainability report dimensi hak asasi manusia berpengaruh positif terhadap kinerja pasar.}

\section{METODA PENELITIAN}

\section{Populasi dan Sampel}

Populasi dalam penelitian ini menggunakan laporan keuangan semua perusahaan yang terdaftar di Bursa Efek Indonesia (BEI) selama tahun 2012-2016. Pemilihan sampel dalam populasi ini menggunakan metode purposive sampling dengan kriteria tertentu sebagai berikut:

1) Perusahaan terdaftar di BEI dari tahun 2012-2016.

2) Laporan tahunan dapat diakses dari sumber data

3) Laporan keuangan menyediakan informasi yang berhubungan dengan variabel.

4) Laporan keuangan disajikan dalam rupiah.

Tabel 1. Prosedur Pemilihan Sampel

\begin{tabular}{|l|l|l|l|l|l|l|l|}
\hline No. & Keterangan & $\mathbf{2 0 1 2}$ & $\mathbf{2 0 1 3}$ & $\mathbf{2 0 1 4}$ & $\mathbf{2 0 1 5}$ & $\mathbf{2 0 1 6}$ & Jumlah \\
\hline $\mathbf{1 .}$ & $\begin{array}{l}\text { Perusahaan yang } \\
\text { terdaftar di BEI untuk } \\
\text { tahun 2012-2016. }\end{array}$ & 425 & 464 & 454 & 454 & 460 & 2257 \\
\hline 2. & $\begin{array}{l}\text { Laporan Tahunan yang } \\
\text { tidak tersedia dari } \\
\text { sumber data yang } \\
\text { digunakan. }\end{array}$ & $(1)$ & $(1)$ & $(1)$ & $(2)$ & $(3)$ & $(8)$ \\
\hline 3. & $\begin{array}{l}\text { Laporan tahunan tidak } \\
\text { dapat diakses }\end{array}$ & $(12)$ & $(11)$ & $(8)$ & $(9)$ & $(10)$ & $(50)$ \\
\hline 4. & $\begin{array}{l}\text { Laporan keuangan tidak } \\
\text { dalam rupiah }\end{array}$ & $\mathbf{( 6 0 )}$ & $\mathbf{( 7 0 )}$ & $\mathbf{( 6 8 )}$ & $\mathbf{( 6 4 )}$ & $(64)$ & $(326)$ \\
\hline & Total Sampel & 352 & 382 & 377 & 379 & 383 & 1873 \\
\hline
\end{tabular}

\section{Jenis dan Sumber Data}

Data penelitian ini menggunakan data sekunder, yaitu data yang diperoleh dari pihak perantara atau data sudah ada sehingga peneliti tinggal mengumpulkannya. Data sekunder 
dalam penelitian ini berupa laporan keuangan dari perusahaan yang terdaftar di BEI periode 2012-2016. Sumber data berasal dari IDX Statistik PIPM Semarang dan situs BEI (www.idx.co.id) serta website harga saham disitus www.yahoofinance.com.

\section{Definisi Operasional dan Pengukuran Variabel.}

Sustainability Report Dimensi Ekonomi adalah aspek ekonomi yang dilaporkan dalam laporan keberlanjutan lebih pada kontribusi perusahaan terhadap besar sistem ekonomi. Pada penelitian ini diukur dengan menggunakan variabel dummy yaitu indeks total pengungkapan dibagi dengan total indeks untuk dimensi ekonomi sebagai berikut: Index $=E c o$ / k. Dimana: Index = Indeks skor setiap dimensi, $E c o=$ Jumlah item yang diungkapkan setiap dimensi, $\mathrm{k}=$ Jumlah item yang diharapkan setiap dimensi.

Sustainability Report Dimensi Lingkungan adalah pengungkapan dari implikasi langsung terhadap ekosistem baik yang hidup maupun yang tidak hidup. Pada penelitian ini diukur dengan menggunakan variabel dummy yaitu indeks total pengungkapan dibagi dengan total indeks untuk dimensi lingkungan sebagai berikut: Index= Env / k. Dimana: Index = Indeks skor setiap dimensi, Env = Jumlah item yang diungkapkan setiap dimensi, k=Jumlah ite m yang diharapkan setiap dimensi.

Sustainability Report Dimensi Sosial adalah informasi yang berhubungan dengan risiko yang diasosiasikan dengan kondisi sosial seperti suap, korupsi, praktek monopoli dan kolusi. Pada penelitian ini diukur dengan menggunakan variabel dummy yaitu indeks total pengungkapan dibagi dengan total indeks untuk dimensi sosial sebagai berikut: Index= Soc/k . Dimana: Index = Indeks skor setiap dimensi, Soc $=$ Jumlah item yang diungkapkan setiap dimensi, $\mathrm{k}=$ Jumlah item yang diharapkan setiap dimensi.

Sustainability Report dimensi hak asasi manusai adalah informasi perusahaan mengenai kondisi hak asasi manusia seperti hak pekerja, keselamatan karyawan, dan sebagainya. Pada penelitian ini diukur dengan menggunakan variabel dummy yaitu indeks total pengungkapan dibagi dengan total indeks untuk dimensi hak asasi manusia sebagai berikut: Index= HAM / k. Dimana: Index = Indeks skor setiap dimensi, HAM = Jumlah item yang diungkapkan setiap dimensi, $\mathrm{k}=$ Jumlah item yang diharapkan setiap dimensi.

Kinerja Pasar diukur menggunakan price earnings ratio (PER) yaitu membandingkan harga saham dengan laba per lembar saham.

\section{Model Regresi}

Pengaruh sustainability report terhadap kinerja pasar dianalisis menggunakan regresi berganda. Model yang digunakan untuk menguji pengaruh dimensi ekonomi (Eco), dimensi lingkungan (Env), dimensi sosial (SoS), dan dimensi hak asasi manusia (HAM) adalah sebagai berikut :

$$
\mathrm{PER}=\beta_{0}+\beta_{1} \mathrm{Eco}+\beta_{2} \mathrm{Env}+\beta_{3} \mathrm{SoS}+\beta_{4} \mathrm{HAM}+\mathrm{e}
$$

Keterangan:

PER = Price Earning Ratio

Eco = Sustainability Report Dimensi Ekonomi

Env = Sustainability Report Dimensi Lingkungan

Sos = Sustainability Report Dimensi Sosial

HAM = Sustainability Report Dimensi Hak Asasi Manusia 


\section{HASIL DAN PEMBAHASAN}

Tabel 2 menampilkan statistik deskriptif variabel-variabel yang digunakan dalam penelitian ini. Dari tabel dapat dilihat bahwa untuk variabel dimensi ekonomi (Eco) memiliki nilai minimum 0,000 , nilai maksimum 0,778 , rata rata 0,426 dan standar deviasi 0,150. Jadi rata-rata sampel variabel Eco hanya 42,6\% dari yang seharusnya. Untuk variabel dimensi lingkungan (Env) memiliki nilai minimum 0,000, nilai maksimum 0,500, rata rata 0,072 dan standar deviasi 0,0150. Jadi rata-rata sampel variabel Env hanya 7,2\% dari yang seharusnya.

Tabel 2. Statistik Deskriptif

\begin{tabular}{|c|c|c|c|c|c|}
\hline & $\mathrm{N}$ & Minimum & Maximum & Mean & Std. Deviation \\
\hline Eco & 753 & 0,00 & 0,78 & 0,43 & 0,15 \\
\hline Env & 753 & 0,00 & 0,50 & 0,07 & 0,08 \\
\hline SoS & 753 & 0,00 & 0,50 & 0,08 & 0,11 \\
\hline HAM & 753 & 0,00 & 0,18 & 0,01 & 0,03 \\
\hline PER & 753 & 2,18 & 25,94 & 11,58 & 4,60 \\
\hline
\end{tabular}

Variabel dimensi sosial (SoS) memiliki nilai minimum 0,000, nilai maksimum 0,500, rata-rata 0,083 dan standar deviasi 0,106. Jadi rata-rata sampel variabel SO hanya 8,3\% dari yang seharusnya.Untuk variabel dimensi hak asasi manusia (HAM) memiliki nilai minimum 0,000, nilai maksimum 0,182, rata rata 0,007 dan standar deviasi 0,026. Jadi rata-rata sampel HAR hanya $0,7 \%$ dari yang seharusnya.

Nilai minimum untuk ukuran KAP sebesar 0,000 dan maksimum sebesar 1,000 dengan rata-ratanya sebesar 0,381. Jadi rata-rata sampel hanya 38,1\% perusahaan diaudit oleh KAP Big Four, sedangkan sisanya sebesar 61,9\% perusahaan diaudit oleh KAP non Big Four.

Variabel PER memiliki nilai minimum 2,180, nilai maksimum 25,943, standar deviasi 4,602, dan rata-ratanya sebesar 11,585 artinya rasio pasar dibandingkan total asetnya 11,585\%. Jadi sampel pada penelitian ini memiliki harga saham yang rendah.

\section{Hasil Pengujian Hipotesis}

Tabel 3 menyajikan hasil analisis regresi hubungan antara sustainability report dan kinerja pasar. Dari tabel dapat dilihat nilai signifikansi t untuk variabel Eco sebesar 0,000 dengan arah negatif. Artinya, variabel dimensi ekonomi berpengaruh negatif terhadap kinerja pasar pada level 1\%. Hasil ini menunjukkan bahwa perusahaan yang melakukan pengungkapan sustainability report dimensi ekonomi menyebabkan kinerja pasar yang diukur dengan price earnings ratio mengalami penurunan. Hasil ini agak membingungkan karena seharusnya upaya perusahaan untuk mengungkapkan dampak perubahan ekonomi makro dapat membantu investor menilai prospek perusahaan ke depan. Ada kemungkinan informasi dimensi ekonomi kurang dipercayai investor sehingga mereka melakukan analisis sendiri dalam menilai dampak ekonomi makro terhadap prospek perusahaan ke depan. Dengan demikian, hipotesis pertama pada penelitian ini ditolak. Sementara itu, nilai signifikansi t untuk variabel Env sebesar 0,000. Artinya, variabel dimensi lingkungan berpengaruh positif signifikan terhadap kinerja pasar pada tingkat 1\%. Dengan demikian, hipotesis kedua pada penelitian ini diterima. Nilai signifikansi t untuk variabel SoS sebesar 0,021. Artinya, variabel sosial ekonomi berpengaruh positif signifikan terhadap kinerja pasar. Dengan demikian, hipotesis ketiga pada penelitian ini diterima. Nilai signifikansi t untuk 
variabel HAM sebesar 0,114. Artinya, variabel dimensi hak asasi manusia tidak berpengaruh terhadap kinerja pasar. Dengan demikian, hipotesis keempat pada penelitian ini ditolak.

Tabel 3. Sustainability Report dan Kinrja Pasar

\begin{tabular}{|c|l|l|l|l|l|}
\hline \multirow{2}{*}{ Model } & \multicolumn{2}{|l|}{$\begin{array}{l}\text { Unstandardized } \\
\text { Coefficients }\end{array}$} & $\begin{array}{l}\text { Standardized } \\
\text { Coefficients }\end{array}$ & \multirow{2}{*}{$\mathrm{T}$} \\
\cline { 3 - 4 } & $\mathrm{B}$ & $\begin{array}{l}\text { Std. } \\
\text { Error }\end{array}$ & Beta & Sig. \\
\hline (Constant) & 12,717 & 0,485 & & 26,227 & 0,000 \\
Eco & $-7,32$ & 1,081 & $-0,239$ & $-6,774$ & 0,000 \\
Env & 19,559 & 2,035 & 0,345 & 9,612 & 0,000 \\
SoS & 3,542 & 1,526 & 0,082 & 2,321 & 0,021 \\
HAM & $-9,59$ & 6,061 & $-0,054$ & $-1,582$ & 0,114 \\
\hline
\end{tabular}

\section{KESIMPULAN}

Wacana tentang perubahan iklim dan tanggung jawab sosial perusahaan telah mengalihkan perhatian investor terhadap isu-isu lingkungan. Agar minat investor terhadap saham perusahaan tetap terjaga, perusahaan harus memberikan respon terhadap perubahan perilaku investor yang lebih menekankan pada aspek-aspek sosial lingkungan. Kondisi keuangan yang baik saja belum cukup untuk menyakinkan investor dalam membeli saham perusahaan jika pertumbuhan tersebut harus mengorbankan lingkungan alam dan sosial. Perlu perhatian serius agar perusahaan bertumbuh secara sustainable (berkelanjutan). Dengan tuntutan para stakeholder terhadap pertanggungjawaban sosial dan lingkungan maka perusahaan harus dengan suka rela mengungkapkan laporan keberlanjutan atau sustainability report.

Penelitian ini bertujuan untuk menguji pengaruh pengungkapan sustainability report terhadap kinerja pasar perusahaan. Kinerja perusahaan diproksikan dengan price earnings ratio. Perusahaan yang melaporkan sustainability report diprediksi memiliki kinerja keuangan yang baik. Lebih spesifik, ada empat dimensi dari sustainability report yang akan diuji yaitu dimensi ekonomi, dimensi lingkungan, dimensi sosial, dan dimensi hak asasi manusia. Perusahaan yang melaporkan sustainability report diprediksi memiliki profitabilitas yang tinggi dan kinerja saham yang baik.

Pengujian hipotesis menggunakan analisis regresi menunjukkan hasil sebagai berikut: 1) Sustainability Report dimensi ekonomi berpengaruh negatif terhadap kinerja pasar. 2) Sustainability Report dimensi lingkungan berpengaruh positif terhadap kinerja pasar. 3) Sustainability Report dimensi sosial berpengaruh terhadap kinerja pasar. 4) Sustainability Report dimensi hak asasi manusia tidak berpengaruh terhadap kinerja keuangan PER. 


\section{DAFTAR PUSTAKA}

Ameta, 2011. Pengaruh Manajemen Laba, Mekanisme Corporate Governance, dan Kualitas Audit Terhadap Kinerja Keuangan Pada Perusahaan Barang Konsumsi Yang Terdaftar di Bursa Efek Indonesia. Diunduh dari: http://repository.usu.ac.id/handle/123456789/29686?show=full

Burhan, A., and R. Wiwin. 2012. The Impact of Sustainability Reporting on Company Performance. Journal of Economics, Business, and Accountancy Ventura 15(2).

Lujie, C. 2015. Sustainability and company performance: Evidence from the manufacturing industry. Linköping Studies in Science and Technology, Dissertations, No. 1698.

DeAngelo, L.E. 1981. Auditor Size and Auditor Quality. Journal of Accounting and Economics 3 (3): 183-199.

Ernst and Young, 2013. Value of Sustainability Reporting. A study by Ernst \& Young LLP and the Boston College Center for Corporate Citizenship. Diunduh dari: http://www.ey.com/Publication/vwLUAssets/EY-lets-talksustainability/\$FILE/EY-lets-talk-sustainability.pdf

Global Reporting Initiative. (2011). Sustainability Reporting Guidelines, Version 3.1.

Jackson, A. and D. Davis. 2011. Sustainability and Triple Bottom Line Reporting - What is it all about? International Journal of Business, Humanities and Technology 1 (3).

Munawir. 2000. Analisis Laporan Keuangan. Jogjakarta: Liberty.

Ratnasari, Y. dan A. Prastiwi. 2010. Pengaruh corporate governance terhadap luas tanggung jawab sosial perusahaan di dalam sustainability report. Skripsi. Universitas Diponegoro.

Josua, T. dan Semuel, H. 2014. Pengungkapan Sustainability Report dan Kinerja Keuangan. Jurnal Akuntansi dan Keuangan 16 (2) : 88-101. SSN 1411-0288 print / ISSN 2338-8137 online. 